\title{
Occurrence of Conspecific in the Neighboring Space Influence on Flight Initiation Distance in Cape Hare Lepus capensis under Human Stimuli
}

\author{
Muhammad Zaman ${ }^{1 *}$, Bushra Allah Rakha ${ }^{2 *}$, Kwasi Wrensford ${ }^{3 *}$, Mengyan Zhu ${ }^{1^{*}}$, \\ Longcheng Fan ${ }^{*}$, Guangshun Jiang1\#
}

${ }^{1}$ Feline Research Center of National Forestry and Grassland Administration, College of Wildlife and Protected Area, Northeast Forestry University, Harbin, China

${ }^{2}$ Department of Wildlife Management, PMAS Arid Agriculture University, Rawalpindi, Pakistan

${ }^{3}$ Museum of Vertebrate Zoology and Department of Integrative Biology, University of California, Berkeley, USA

Email: "jgshun@126.com

How to cite this paper: Zaman, M., Rakha, B.A., Wrensford, K., Zhu, M., Fan, L. and Jiang, G. (2020) Occurrence of Conspecific in the Neighboring Space Influence on Flight Initiation Distance in Cape Hare Lepus capensis under Human Stimuli. Open Journal of Ecology, 10, 380-395.

https://doi.org/10.4236/oje.2020.106024

Received: May 12, 2020

Accepted: June 9, 2020

Published: June 12, 2020

Copyright $\odot 2020$ by author(s) and Scientific Research Publishing Inc. This work is licensed under the Creative Commons Attribution International License (CC BY 4.0).

http://creativecommons.org/licenses/by/4.0/

\begin{abstract}
Optimal escape theory predicts that animals would balance the costs and benefits of flight. One cost of not fleeing is the ongoing cost of vigilance for upcoming environmental threats. Our results show that FID increases for vigilant hares with predator starting distance, due to the costs acquired by continuing to scan for ecological dangers. The presence of conspecifics within proximity distance for social hare was reduced FID due to collective vigilance, while a solitary animal had greater FID, due to less cooperative defense for predator detection. In both seasons, detection and flight initiation distance of the focal hare increased in open habitat due to a higher probability of detection for upcoming danger, while dense cover provided concealment but reduced the probability of detecting an incoming threat, reducing FID. Moreover, proximity to roads and the nearest refuge significantly influenced anti-predator risk by compensation energy to cope with approaching stimuli. In a landscape with heavy human hunting in retaliation to plantations damage has modified the natural behavior of the hare in the Shigar valley. The findings are discussed in the context of hare FID by humans and the suggestions for management and mitigation of human-wildlife conflict are also considered.
\end{abstract}

\section{Keywords}

Alert Distance, Distance to Refuge, Flight Initiation Distance (FID), Group Size Effect, Starting Distance, Social or Solitary Hare

*These authors contributed equally to this work. 


\section{Introduction}

Prey understanding of predation risk is a crucial driver of escape decision [1]. One such decision, termed Flight Initiation Distance (FID) [2], is the straight line distance between an approaching predator and prey at which a prey begins flight. That decision of if and/or when to flee can have significant energetic fitness trade-offs [3]. Flight responses can also fluctuate according to previous exposure to humans [4], individual personality [5], and hunting pressure [4] [6] [7]. Hunted animals tend to exhibit greater FIDs than non-hunted ones (e.g., Masai giraffes Giraffa camelopardalis tippelskirchi [4] [6] [7] [8]); reindeer; Rangifer tarandus [9]), and temporal variations in human presence elicit changes in FID [10]. Nonetheless, habituation of wild animals to human presence is widespread [11] [12]. Directly attributing variation in escape behavior to fitness is problematic [13]; however previous studies on different taxa have recognized survival effects in animals escaping from humans. For example, yellow-bellied marmots $M$. flaviventris that made suboptimal decisions as to relative time spent foraging versus hiding from humans had lower body mass and increased over-winter mortality [14]. Social and ecological factors may impact prey escape reactions to human and non-human predators [15] [16]. The effect of group size on FID is well documented in terrestrial organisms, but highly inconsistent between studies, ranging from strong positive [17], to negative effects [18]. Effects of sex and reproductive status in escape decisions are also influential and arguably more consistent, with females generally exhibiting greater FID and/or $\mathrm{AD}$, particularly those with young (e.g., Alpine marmots M. marmota [19]). Mammalian prey species are very sensitive to spatial variables in their environment [20] [21], particularly those affecting visibility and predator recognition probability such as topography and vegetation height. For example, the brown hare Lepus europaeus and cape hare Lepus capensis show earlier escape responses in shorter grass [21] [22] and, for burrowing species, vicinity to a refuge is a significant predictor of FID (e.g., plateau pika Ochotona curzoniae [23]).

One key determinant of FID is the group size [10]. Usually, the larger the group, the greater the overall vigilance, therefore the more ears/eyes to detect predators [16]. In turn, social animals should flee at a greater distance because of the earlier predator detection (e.g., Gray-Cheeked Mangabeys Lophocebus albigena [24]). Conversely, it is also possible that warier-albeit solitary-animals such as hares could increase the probability of predator detection through vigilance (e.g. Brown Mouse Lemurs Microcebus rufus [25]). FID is an outstanding metric for measuring an individual's fearfulness under certain conditions [26], and flight response is also studied to recognize the areas where the species are not influenced by humans [27]. This index has been studied in several species from different taxa, particularly in birds [28], fishes or lizards [7] [29] [30], ungulates and small mammals [23] [31] [32] [33]. However, no study has been conducted so far on the cape hare, a species that occurs in a heavily hunted 
landscape in the Karakorum Range. The current study will be helpful to know least focus cape hare behaviors in the Shigar Valley, this study will also predict to control illegal hunting and poaching of hare as well as implications for management of habitats resource.

Additionally, cost-benefit models, such as the economic model of flight expect that FID will be the optimized relatively than maximized base on factors linked to direct and indirect tradeoffs of fleeing or not [34]. For example, a biotic factor, such as human stimuli are known to influence FID of animal species in the threatening landscape [10] [35]. Additionally, detection of a predator by vigilant animals can be anticipated in low-cover/open habitats area than in high cover ones [10] [21] [22] [35]. The aims of our study were to test association between hare FID and social hare in areas under high hunting pressure, with the underlying assumption that solitary hares would be predictable to have a higher perception of anthropogenic risk and therefore flee when hunters are closer. We also tested the following hypotheses: 1) Solitary animals have greater FIDs than social ones due to the group size effect when predation risk occurs, and it is predicted that the group sizes of animal influenced predation risk [23]. Starting distance is thus extensively measured as a significant parameter to include in FID analyses. Escape theory predicts that prey's decision to flee depends on a predation risk calculation, which is higher by watching the upcoming predator. We define prey refuge to assume that anti-predator decisions are also influenced by habitat features, especially where it affects visibility and exposure probability. Variables that influence visibility and detectability include distance to a refuge and vegetation height.

2) Hunting and human infrastructures such as roads and vehicles are predicted to have a negative influence on hare flight response. The accessibility of risky shelter in the landscape not only affects the spatial dispersal of the prey themselves, but a cause by human persecution can also significantly influence prey feeding efficiency and vigilance behavior.

\section{Materials and Methods}

\subsection{Study Area}

We conducted our study in the Shigar Valley within the Karakoram mountain range, located along the North bank of the river Indus in Northeast Pakistan (Figure 1). It lies at $25^{\circ} 25^{\prime} 32^{\prime \prime} \mathrm{N}$ latitude and $75^{\circ} 42^{\prime} 59^{\prime \prime} \mathrm{E}$ longitude and covers an area of $4373 \mathrm{~km}^{2}$ with an altitudinal range of 2260 to $8611 \mathrm{~m}$ a.s.l. including K2 (8611 m), Broad Peak (8047 m), Angel Peak (6858 m), and Skil Brum (7360 m) [10]. Annual precipitation around $200 \mathrm{~mm}$ with a maximum of almost $600 \mathrm{~mm}$ at elevations of $3962 \mathrm{~m}$ and snow depth maximum of 0.304 meter and a minimum of 0.127 meter. Shigar 1, is located in Karakoram range part, at the elevation of $2527 \mathrm{~m}$ above sea level (asl) the North-East. The most common plant species are wild rose Rosa webbiana, sea buckthorn Hippophae rhamnoides and berberis Berberis lyceum [36]. The Cape hare is an important prey species for 


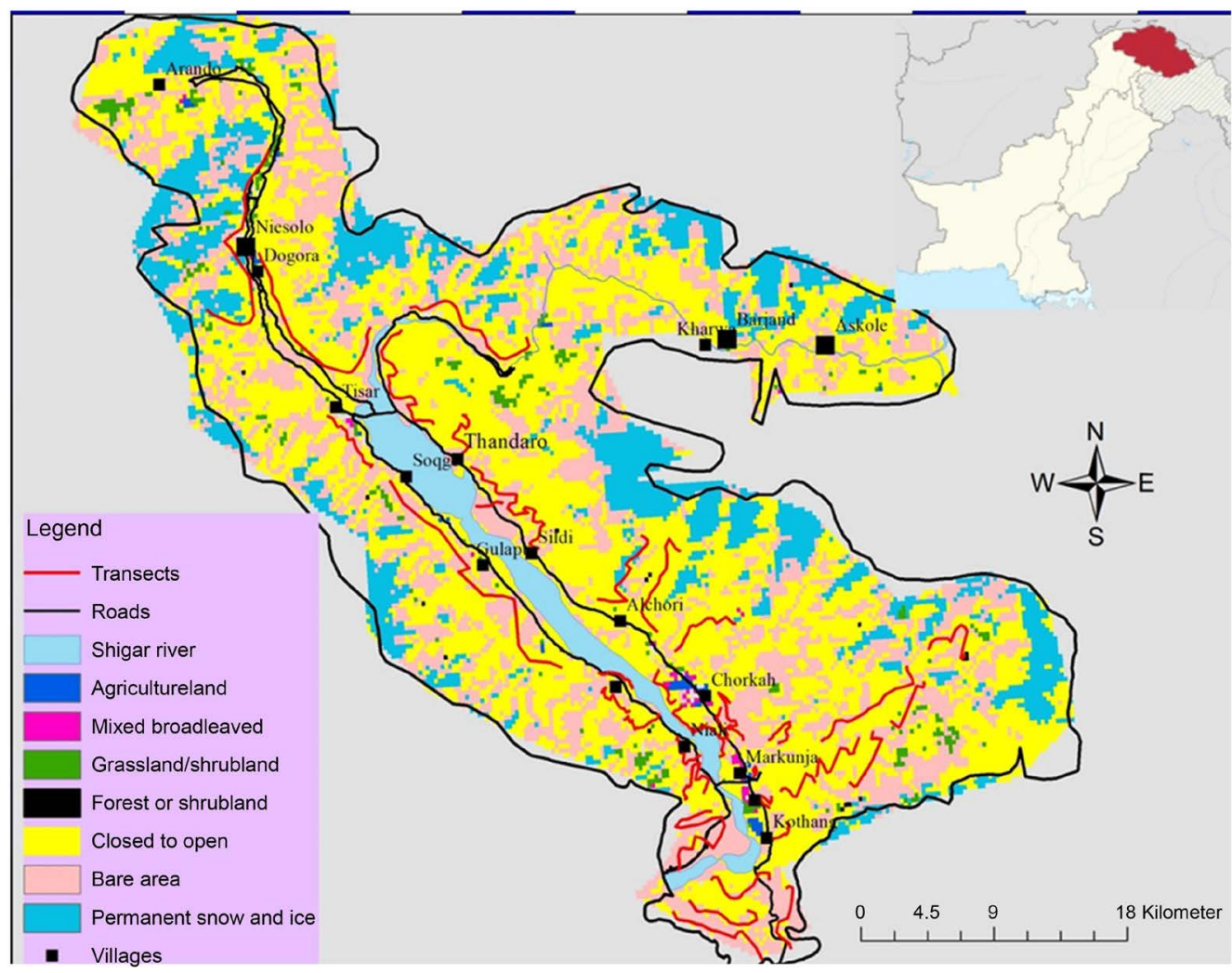

Figure 1. Sampling sites selection in the Shigar Valley, Karakoram range, in both winter and summer. Note, each sampling session we walked out the same transects. Source of map collected from published article by Zaman et al., 2020.

the Golden eagle Aquila chrysaetos, Tibetan wolf Canis lupus, Red fox Vulpes vulpes and Snow leopard Panthera uncia [10] [21] [36]. The Karakoram range is a mostly unexplored landscape due to rugged, deadly mountainous terrain covered with narrow valleys, ravines, cliffs and ridges, and mostly glaciated mountain crests. We used four distinct types of vegetation structures to categorize our study sites: 1 ) closed to open ( $>15 \%)$ herbaceous vegetation or shrubland $(20 \%$ $50 \%)(<5 \mathrm{~m}) ; 2)(50 \%-70 \%)$ grassland and barren lands ( $<3 \mathrm{~m}) ; 3)(20 \%-50 \%)$ deciduous forest plantation ( $>5 \mathrm{~m}$ ) mixed agriculture land (villages); 4 ) closed to open $(>15 \%)$ broadleaved or needle-leaved, evergreen or deciduous forest ( $>5$ m) (Figure 1). We performed supervised and unsupervised classification use for habitat types [10].

\subsection{Data Collection}

\section{Flight initiation distance records}

Our study was conducted over three consecutive years, in Shigar Valley. We recorded data in summer (3 June-5 September) and autumn (25 October-27 December), for years 2015 and 2019, and in summer of 2020 (2 April to 12 May). At the beginning of each sampling session, we arrived at a distance from the hare that allowed a clear view of the target animals without instigating flight or alert behavior. We recorded the behavioral activities of the focal animal (usually se- 
lected as the closest to the investigators) through observations made with $10 \times$ 42 binoculars [10]. We categorized initial activities as either "watching" or "foraging and other activities" [16] [23]. We recorded whether the hare was solitary (when there was no conspecifics within $3 \mathrm{~m}$ ), or groups (when there was one or more conspecifics within $3 \mathrm{~m}$ ) and focal hare was measured as nearest-neighbor distance [10].

At the start of each sampling session, two observers walked straight towards the focal animal while keeping visual contact at a standardized speed of 0.5 to 1 $\mathrm{m} / \mathrm{s}$ (practiced prior to the field data collection) [10] [35]. Observers changed between sampling sessions, but wore similar clothing [10] [37]. The observer dropped a flag at each of the following: 1) onset location of the approach; 2) experimenter location when the focal hare responded to the approach (e.g. by moving its head in experimenter's direction); and 3) experimenter location when the hare started to flee, usually by running into a near refuge. Subsequently, the following were recorded using a standard tape measure: 1) starting distance, SD (first flag to initial position); 2) alert distance, AD (second flag to initial position); and FID (third flag to initial position), all as straight-line measurements, in meters (Blumstein et al., 2018; Zaman et al., 2019) (see Figure 2). We also

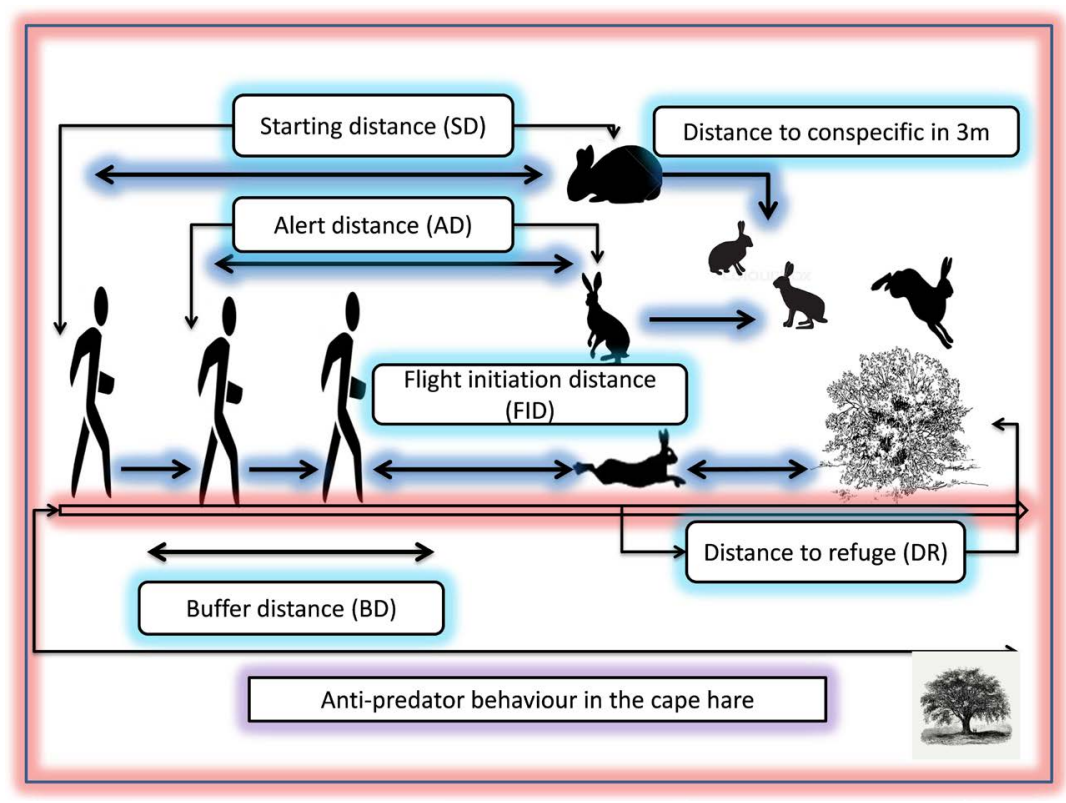

Figure 2. Graphical representation of the five anti-predator indicators measured in this study. Starting distance (SD) is measured as the distance at which an approaching human begins to approach a prey. Alert distance $(\mathrm{AD})$ is measured as the distance at which prey reacts by orienting in the direction of the approaching human. Flight initiation distance (FID) is measured as the human-prey distance when the prey begins to flee. Pre-detection distance measures the duration a prey takes to become alert of an approaching human (i.e., the difference between SD and AD). Buffer distance, is an estimate of tolerance considered as the distance at which a prey escaped after being alerted by an approaching human (i.e., the alteration distance between $\mathrm{AD}$ and FID), Distance to near refuge, were considered a distance between FID and nearest vegetation patches, social (i.e., neighboring distance of conspecific in $3 \mathrm{~m}$ ) or solitary (absence of conspecific within $3 \mathrm{~m}$ ). 
measured the hares distance to the nearest refuge. Additionally, we measured environmental variables which reflected our hypotheses, for each focal hare. We recorded them with the aid of a rangefinder, or we obtained environmental variables using Arc GIS 10.2 (see Table 1) (Blumstein et al., 2018; Zaman et al., 2019). To prevent habituation, the observer walked a least of $100 \mathrm{~m}$ away from a sampled site after each trial, thereby reducing the probability that other individuals observed the trial. We piloted FID trials at intervals of $>15$ days to avoid habituation of the animals in each season (Zhang et al., 2015).

\subsubsection{Habitat Covariates}

We surveyed the focal hare's habitat based on cover type [38], and defined the habitat as open area when its vegetation height was low $(<5 \mathrm{~m})$ and dense when its vegetation height was high $(>5 \mathrm{~m})$ with low visibility of animal. The habitat types were extracted by polygons, and we measured distance to nearest anthropogenic roads, vegetation structure by ArcGIS (10.2, see Table 1) [39].

Table 1. Description of the explanatory variables included in the generalized linear mixed-effect models for hare FID including three environmental predictors.

\begin{tabular}{|c|c|c|}
\hline Fixed variables & Description of variables & Data type \\
\hline Group size & $\begin{array}{l}\text { Socials, Number of conspecifics within } 3 \mathrm{~m} \text { of focal hare, } \\
\text { solitary (when there was no other animal within } 3 \mathrm{~m} \text { of focal } \\
\text { hare) }\end{array}$ & Binary \\
\hline Initial activities & $\begin{array}{l}\text { The type of animal activity when observer started the } \\
\text { approaching: either foraging or vigilant }\end{array}$ & Binary \\
\hline Starting distance & $\begin{array}{l}\text { Distance }(\mathrm{m}) \text { between experimenter and focal hare when the } \\
\text { former begins approach }\end{array}$ & Continuous \\
\hline Distance to refuge & $\begin{array}{l}\text { Distance }(\mathrm{m}) \text { from each focal hare flight position to the } \\
\text { nearest vegetation patches }\end{array}$ & Continuous \\
\hline Trails number & Each number of trails was observations carried out for hare. & Continuous \\
\hline Year & Year of study: 2015, 2019, 2020 & Categorical \\
\hline Seasons & Summer and winter observations for focal hare & Binary \\
\hline \multicolumn{3}{|l|}{ Topography } \\
\hline Elevation & $\begin{array}{l}\text { Altitudes converted into DEM by TIN in 3D analysis with } \\
\text { projected UTM }(43-\mathrm{N}) \text { for each coordinate of trials }\end{array}$ & Continuous \\
\hline Viewshed & $\begin{array}{l}\text { Viewshed analysis determines areas visible and not visible on } \\
\text { a triangulated irregular network (TIN) from one (e.g., dense } \\
\text { sampling sites) to many observation sites }\end{array}$ & Continuous \\
\hline Vegetation height & $\begin{array}{l}\text { Forest/shrubland height estimated, Tall }(>5 \mathrm{~m}) \text {, grassland, } \\
\text { barren land Short }(<5 \mathrm{~m})\end{array}$ & Binary \\
\hline \multicolumn{3}{|l|}{ Anthropogenic factor } \\
\hline Presences of humans & $\begin{array}{l}\text { Presence of additional pedestrians within each transects (e.g. } \\
\text { tourist hikers, livestock farmers, hunters) }\end{array}$ & Binary \\
\hline Road & $\begin{array}{l}\text { Distance from each location point to the periphery of the } \\
\text { nearest roads including high-traffic and low-traffic roads }\end{array}$ & Continuous \\
\hline
\end{tabular}




\subsubsection{Data Analyses}

Initially, data were analyzed within a fitted general linear models (GLM) null hypothesis significance testing (NHST) framework computed in R statistical software version 3.5.0 (www.r-project.org) (R Core Development Team 2018). The measured response variable $(\mathrm{m})$ was over-fitted with full and sub set of models, so we investigated collinearity of explanatory variables using variance inflation factor (VIF). Variables with VIF values of $>3$ or averaged values across all variables of $>3$ were reflected to be collinear and were thereafter removed (Guo et al., 2017). Finally, we found no indication of correlation among the predictors used in the analysis (all the correlation coefficient were $(r<0.61)$, with remaining candidate fixed variables explained in Table 1 . We fitted generalized linear mixed-effect models with a Poisson error structure using the R packages lme4 and lmerTest [37]. We assumed that risk influence on a hare's FID may be related to 1) group size effect, 2) terrain types and 3) anthropogenic threats. We built three different separate candidate models to fulfill the requirement of the hypothesis test as well as the effect of habitat covariates on FID. Firstly, we built a model (a) to check group size effect; we used only 7 fixed factors and ran four models. Secondly, we created a model (b); at the terrain type used 3 fixed factors and ran four models. Thirdly, we constructed models (c), anthropogenic factor level, we used 2 fixed factors in the models and ran three models (Guo et al., 2017) (see, Table 2(a)). Again, each transect's ID of focal hare sampling size was included as a random factor to check variation in FID for each of the three candidate models (Blumstein et al., 2018). Because of the recognized relationship of starting distance and group size with FID of focal hare in each sample session [40] [41], these two fixed effects variables were combined with every subset of the three predictor variables, because intruder starting distance and group size are known to influence FID [23] [26] [42]. At the three levels of analysis, for each response variable, we performed a model selection to rank all the possible models, including the null model, as each of them could represent a different a priori hypothesis [10]. Ranking was made by using Akaike's information criterion corrected for small samples (AICc): we selected best models, i.e. having $\triangle \mathrm{AICc} \leq 2$, and we calculated Akaike model weight ( $\omega$ i) and subsequently we estimated parameters (standardized $\beta$ coefficients, standard errors and 95\% confidence intervals) from the best models (Fattorini and Ferretti, 2019).

\subsubsection{Ethical Approval}

We conducted this observational non-invasive study according to the regulations for animal welfare and conservation under the Gilgit-Baltistan Wildlife Preservation Act 1975. In the study, the field data were collected following ethical review by Northeast Forestry University, Harbin, China, following their recommendations for the use of animals in research and approving PhD study "2016DFH425". The authors obeyed with the wild animal protection law of the People's Republic of China. 
Table 2. (a) GlMMs selected models of Flight initiation distance (FID) for three environmental predictor, each with number parameter $(\mathrm{K})$ and delta AICC $\leq 2$, Akaike model weights ( $\omega \mathrm{i})$, and yearly focal hare of specific transects ID were random effects. Note; IA, initial activities, $\mathrm{SD}$, is starting distance, $\mathrm{DR}$, distance to refuge, $\mathrm{VH}$, vegetation heights; (b) Standardized coefficients ( $\beta$ ), standard errors (SEs) and $95 \%$ confidence intervals (95\% CIs) of best models. Asterisks mark the 95\% confidence intervals which do not include (0).

(a)

\begin{tabular}{ccccc}
\hline Indicator model retained & k & AICc & $\Delta$ AICc & $\grave{\varphi}$ \\
\hline (a) FID group size + IA + SD + DR + (focal animal) & 6 & 211.73 & 0 & 0.65 \\
FID group size + IA + SD + DR + seasons + (focal animal) & 7 & 250.28 & 1 & 0.41 \\
FID group size + IA + SD + DR + year + season + (focal animal) & 8 & 250.28 & 2.006 & 0.41 \\
(b) FID viewshed + vH + (focal animal) & 4 & 240.51 & 0 & 0.68 \\
(c) FID presence of humans + roads (focal animal) & 4 & 211.71 & 0 & 0.64 \\
FID group size + presence of humans + roads + (focal animal) & 5 & 213.69 & 2.953 & 0.24 \\
\hline
\end{tabular}

(b)

\begin{tabular}{ccccc}
\hline Indicator & Predictor & B & SE & 95\% CI \\
\hline FID (focal animal) variance $=0.012$ & Intercept & -1.44 & 0.72 & -1.95 to $-0.35^{*}$ \\
\cline { 2 - 4 } (a) & Group size (solitary) & 0.86 & 0.25 & 0.25 to $0.67^{*}$ \\
& Initial activities (watching) & 0.02 & 0.41 & 0.74 to $0.80^{*}$ \\
& Starting distance & 0.64 & 0.36 & 0.19 to $0.39^{*}$ \\
FID (focal animal) variance $=-0.103$ & Distance to refuge & -0.65 & 0.33 & -0.20 to $-0.01^{*}$ \\
& Intercept & -1.45 & 0.51 & -3.06 to $-0.82^{*}$ \\
& Viewshed & -0.96 & 0.40 & -2.08 to 0.40 \\
(b) & Vegetation Height (short) & 0.32 & 0.47 & 0.26 to $2.73^{*}$ \\
FID (focal animal) variance $=-0.676$ & Intercept & -2.52 & 0.94 & -0.01 to 2.48 \\
& Presences of humans & -0.01 & 0.14 & -1.52 to $-0.07^{*}$ \\
& Distance to roads & -0.32 & 0.54 & -1.23 to $-0.06^{*}$ \\
\hline
\end{tabular}

\section{Results}

\section{Flight response in relation to habitat covariates}

We collected focal hare flight responses in the summer $(n=140)$ and winter $(n=64)$ sample session from years 2015-2019 and 2020 in the selected sample trails. In both seasons, we had 204 observations on 56 conspecific focal hares (mean 0.8; range 1 - 3 flushes). All variation in our best models was explained by four anti-predator variables: group size, initial activity, starting distance and distance to near prey refuge (AICc: 211.73; weights: 0.659; Table 2(a)). Furthermore, we observed a greater positive significant effect on FID for vigilant and solitary hares compared to foraging and social hares (Table 2(b); Figure 3(a) \& Figure 3(b)). Moreover, FID was positively correlated with the intruder starting distance $(\mathrm{n}=121,0.04$ to $8.12 \mathrm{~m}$; Table $2(\mathrm{~b})$ ). Besides, group size and 

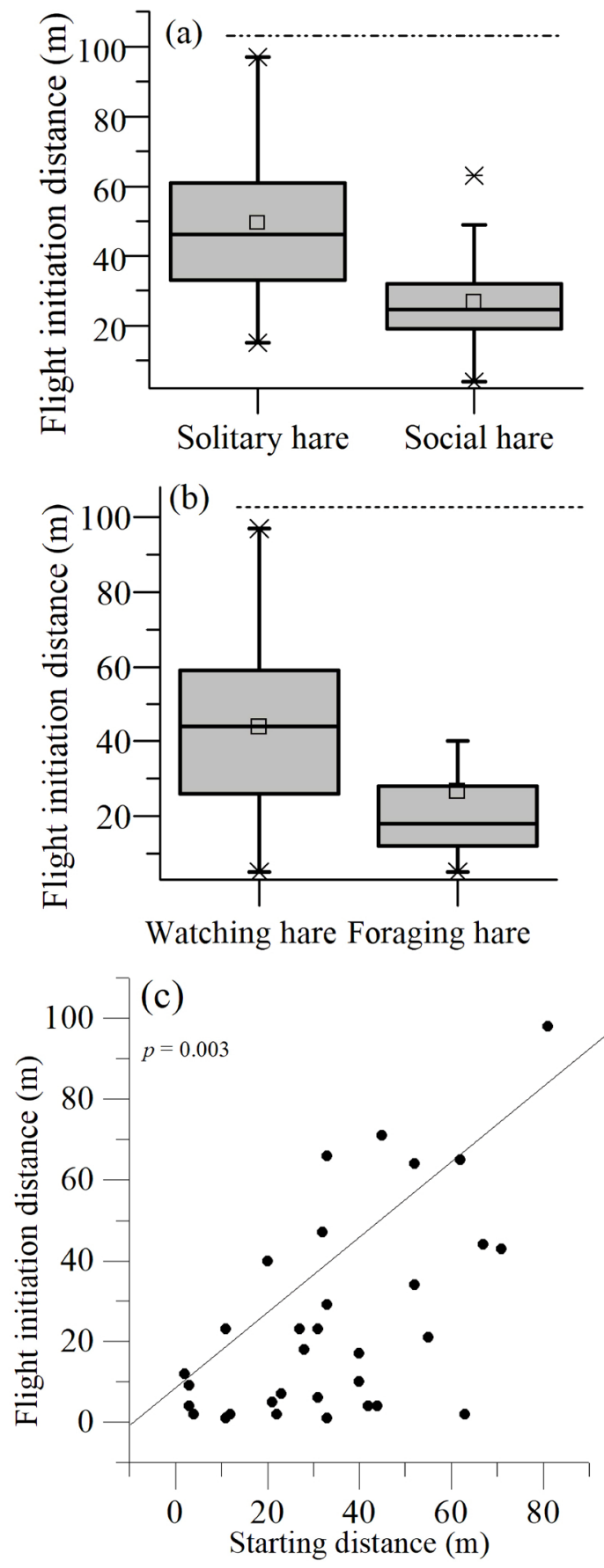

Figure 3. Difference in flight initiation distance (m) (a) between social and solitary hares and (b) between vigilant and foraging hares. Dotted line showed the significance mean difference between companion and initial activities. (c) The relationship between starting distance (m) and response variable FID with significant effect in all models of generalized linear mixed-effect models.

starting distance were not consistent both full as well subset model at terrain type candidate model, but then again the remaining predictor was explained by two variables (AICc: 240.51; weights: 0.689; Table 2(a)), At the terrain types candidate model, FID was poorly explained by the viewshed (visibility of ap- 
proaching threat at different sampling trails), however a positive relationship was observed between FID and vegetation (Table 2(b)).

At the anthropogenic level, the group size of hare did not incorporate the best candidate model. Additionally, at the anthropogenic predictable level observation, the candidate model was best explained by two remaining explanatory variables (AICc: 211.71; weights: 0.648; Table 2(a)). In the landscape level, the occurrence of human $(\mathrm{n}=271)$ and near distance to traffic roads $(\mathrm{n}=78)$ negatively influence FID of either conspecific or heterospecific groups (Table 2(b)). Our responses variable was also correlated with random factors in each explanatory variable and also diverse effect amongst the three different types of environmental predictors (a, variance: $0.012 ; b,-0.103 ; c,-0.676$ ) in the best incorporated models (Table $2(\mathrm{~b})$ ).

\section{Discussion}

\section{Flight response of Cape hare to habitat factors}

The stimuli of humans explained by hypothesis that in both cases of solitary and social hare influenced by environmental threats, although solitary animals were more susceptible to predation risk due to lack of multiple monitors within a proximity distance to cope upcoming dangers (Figure 3(a)). Inversely, the presence of a conspecific in the neighboring space in the landscape was predicted to make prey more vigilant to approaching threats by defining occurrences of group size effect (Figure $3(\mathrm{~b})$ ). It is assumed that hare vigilance can alter through spatial and temporal scales to expand resource gain and decrease the danger of predation [43]. These results are similar to that solitary and vigilant animals are susceptible to flight [23] [44]. Social and foraging hare's reduced flight response was explained by the probability of predator detection related to group size and animal decision [45] [46].

For example, under the detection hypothesis [13] [30], larger groups allow earlier or better predator detection, resulting in greater flight initiation distance [47], but the dilution hypothesis [48], posits that animals in large groups limit their individual chances of being captured or confuse predators. In animal species, living in clusters permits an individual to decrease predation risk through greater predator recognition, or the "many-eyes hypothesis" [49]. For example, Bank swallows Riparia riparia mobbed predators sooner in larger colonies, suggesting faster detection [49]. In saddlebacks Saguinus fuscicollis, vigilance increases with increasing nearest-neighbor distance, indicative of the dilution effect [51]. It seems to be beneficial for group members to use warning signals, and several studies demonstrate this to be the case in sciurids [52]. Various studies have found an effect of nearest-neighbor distance on the vigilance of an animal (e.g., Golden marmots Marmota caudata aurea [10]). One of the main benefits of group living is assumed to be easier detection of predators in large rather than small groups ("many-eyes" hypothesis; meerkats, Suricata suricata [43]); Columbian ground squirrels, Spermophilus columbianus [44], because 
there are additional individuals that can examine for predators.

What's more, the relationship of intruder starting distance and distance to nearest refuge on hare flight response was also similarly observed in other mammals [23]. We expected that in our study areas human persecution was also altering the daily feeding efficiency of hares; such similar results were described for other hare species, e.g. [10]. It is not known whether the flight initiation distance responses of hare in the present study were ultimately related to increased mortality or reduced reproductive success, but they appear to be consistent with the response ("Flush Early and Avoid the Rush") hypothesis [30]. However, one disadvantage of a study such as this is that, although we consider close-proximity individuals to be of the same group and therefore "social", we lack demographic or other variables, despite their potential significance [53]. We expected that vegetation parameter to significantly influence FID, but viewshed did not have a significant effect. We also supposed that fuelwood collection by local people reduced concealment throughout the landscape and increased the compensation of detection. Hares also spent more time in open vegetation at daytime to decrease predation risk, despite lower quality forage availability [38]. The experimental difference in detection capability relative to landscape assembly may imitate a non-random distribution of individuals in space, which fluctuate in their compassion to distribution into the different habitat level. We assumed that less sensitive individuals would be capable to use open and visible habitats, even when the perceived risk of predation is high, by compensating for the greater risk through bigger vigilance levels. Inversely, more sensitive individuals would select safer, comparatively closed local landscapes, For example, European hares in open habitat are able to run fast, but in dense habitats, prey is anticipated to persist due to the accessibility of refuge [22]. Additionally, plateau pika flee at larger distances from an approaching threat when far from a refuge, as well as vigilant animals run longer distances then foraging animals [23], and i.e. the presence of predators in the landscape also directly or indirectly limited the activities of prey [54].

In our study area we encountered two specimens of hare killed by a vehicle impact on the main roads at night time. The impassibility of freeways and main roads has a negative effect on hare vigilance and spatial abundance [55]. Hunting would be more prevalent during winter when the hares have moved to lower elevation to forage in the deciduous plantations, where they cause damage to seedling of plantation while foraging. For example European hare Lepus europaeus is a typical farmland species that has been adversely affected by livelihood and seedling crops of agriculture land [56]. Further study needs to be conducted on hare and predator density, and how it is affected in this human modified landscape. It will be helpful to know the abundance and habitat assortment of hares in current study areas for conservation and management.

\section{Conclusion}

It is preliminary research conducted on Cape hare flight response to environ- 
mental factors in the remote valley of Karakoram range. Our research revealed the perceived level of both risk (in terms of landscape openness and proximity to human infrastructure) and reward (in terms of habitat quality) influenced the time it took for a hare to detect an approaching threat, and the subsequent time for which the threat was tolerated prior to flight. With illegal hunting pressure in the landscape, presence of humans and roads negatively affect FID as well.

\section{Acknowledgements}

We thank Dr. Jinzhe Qi in Feline Research Center of National Forestry and Grassland Administration. We also thank Prof. P. Wegge at Norwegian University of Science (NMBU) for his constructive comments and thank Dr. Fattorini N. and Dr Tolhurst B. for their statistical contribution as well as editing. Finally, we like to appreciate the first author's parents for their honorable support and brothers Nabi and Anwar for their field supports and data entry. This research was funded by the Fundamental Research Funds for the Central Universities (2572017PZ14), The National Natural Science Foundation of China (NSFC 31872241).

\section{Conflicts of Interest}

The authors declare no conflicts of interest regarding the publication of this paper.

\section{References}

[1] Guinness, S., Van Dongen, W., Guay, P.-J., Robinson, R. and Weston, M. (2019) Evaluating How the Group Size of Domestic, Invasive Dogs Affect Coastal Wildlife Responses: The Case of Flight-Initiation Distance (FID) of Birds on Southern Australian Beaches. In: Makowski, C. and Finkl, C., Eds., Impacts of Invasive Species on Coastal Environments, Springer, Cham, 413-424. https://doi.org/10.1007/978-3-319-91382-7_12

[2] Stankowich, T. and Reimers, E. (2015) Escape Decisions in Mammals. Escaping from Predators: An Integrative View of Escape Decisions. Cambridge University Press, London.

[3] Guay, P.-J., McLeod, E., Cross, R., Formby, A., Maldonado, S., Stafford-Bell, R.E., et al. (2013) Observer Effects Occur When Estimating Alert but Not Flight-Initiation Distances. Wildlife Research, 40, 289-293. https://doi.org/10.1071/WR13013

[4] Sproat, K.K., Martinez, N.R., Smith, T.S., Sloan, W.B., Flinders, J.T., Bates, J.W., et al. (2020) Desert Bighorn Sheep Responses to Human Activity in South-Eastern Utah. Wildlife Research, 47, 16-24. https://doi.org/10.1071/WR19029

[5] Martín, J. and López, P. (2015) Hiding Time in Refuge. In: Cooper Jr. W.E., Ed., Escaping from Predators. An Integrative View of Escape Decisions, Cambridge University Press, Cambridge, 227-262.

https://doi.org/10.1017/CBO9781107447189.010

[6] Stankowich, T. (2008) Ungulate Flight Responses to Human Disturbance: A Review and Meta-Analysis. Biological Conservation, 141, 2159-2173. https://doi.org/10.1016/j.biocon.2008.06.026

[7] Williams, D.M., Nguyen, P.-T., Chan, K., Krohn, M. and Blumstein, D.T. (2020) 
High Human Disturbance Decreases Individual Variability in Skink Escape Behavior. Current Zoology, 66, 63-70. https://doi.org/10.1093/cz/zoz027

[8] Marealle, W.N., Fossøy, F., Holmern, T., Stokke, B.G. and Røskaft, E. (2010) Does Illegal Hunting Skew Serengeti Wildlife Sex Ratios? Wildlife Biology, 16, 419-430. https://doi.org/10.2981/10-035

[9] Baskin, L.M. and Hjalten, J. (2001) Fright and Flight Behavior of Reindeer. Alces, 37, 435-445.

[10] Zaman, M., Tolhurst, B.A., Zhu, M. and Jiang, G. (2019) Increased Flight Initiation Distance (FID) in Golden Marmots (Marmota caudata aurea) Responding to Domestic Dogs in a Landscape of Human Disturbance. Animals, 9, 605. https://doi.org/10.3390/ani9090605

[11] Putri, I.A., Ansari, F. and Susilo, A. (2020) Response of Bird Community toward Tourism Activities in the Karst Area of Bantimurung Bulusaraung National Park. Journal of Quality Assurance in Hospitality \& Tourism, 21, 146-167. https://doi.org/10.1080/1528008X.2019.1631725

[12] Valente, S., Skarin, A., Ciucci, P. and Uboni, A. (2020) Attacked from Two Fronts: Interactive Effects of Anthropogenic and Biotic Disturbances Generate Complex Movement Patterns. Arctic, Antarctic, and Alpine Research, 52, 27-40. https://doi.org/10.1080/15230430.2019.1698251

[13] Simpson, S.D., Radford, A.N., Nedelec, S.L., Ferrari, M.C., Chivers, D.P., McCormick, M.I., et al. (2016) Anthropogenic Noise Increases Fish Mortality by Predation. Nature Communications, 7, Article No. 10544. https://doi.org/10.1038/ncomms10544

[14] Runyan, A.M. and Blumstein, D.T. (2004) Do Individual Differences Influence Flight Initiation Distance? The Journal of Wildlife Management, 68, 1124-1129. https://doi.org/10.2193/0022-541X(2004)068[1124:DIDIFI]2.0.CO;2

[15] Fardell, L.L., Pavey, C.R. and Dickman, C.R. (2020) Fear and Stressing in Predator-Prey Ecology: Considering the Twin Stressors of Predators and People on Mammals. PeerJ, 8, e9104. https://doi.org/10.7717/peerj.9104

[16] Fattorini, N. and Ferretti, F. (2019) To Scan or Not to Scan? Occurrence of the Group-Size Effect in a Seasonally Nongregarious Forager. Ethology, 125, 263-275. https://doi.org/10.1111/eth.12844

[17] Cooper, W.E., Cooper Jr, W.E. and Blumstein, D.T., Eds. (2015) Escaping from Predators: An Integrative View of Escape Decisions. Cambridge University Press, Cambridge.

[18] Matson, K.D., Cohen, A.A., Klasing, K.C., Ricklefs, R.E. and Scheuerlein, A. (2005) No Simple Answers for Ecological Immunology: Relationships among Immune Indices at the Individual Level Break down at the Species Level in Waterfowl. Proceedings of the Royal Society B: Biological Sciences, 273, 815-822. https://doi.org/10.1098/rspb.2005.3376

[19] Louis, S. and Le Beere, M. (2000) Adjustment in Flight Distance from Humans by Marmota marmota. Canadian Journal of Zoology, 78, 556-563. https://doi.org/10.1139/z99-242

[20] Mendes, C.P., Carreira, D., Pedrosa, F., Beca, G., Lautenschlager, L., Akkawi, P., et al. (2020) Landscape of Human Fear in Neotropical Rainforest Mammals. Biological Conservation, 241, Article ID: 108257. https://doi.org/10.1016/j.biocon.2019.108257

[21] Zaman, M., Rakha, B., Bao, H., Vitekere, K. and Jiang, G. (2020) Effect of Habitat Factors and Predator Density on the Spatial Abundance of Cape Hare (Lepus ca- 
pensis) in the Karakorum Range. Applied Ecology and Environmental Research, 18, 2921-2934.

[22] Weterings, M.J., Zaccaroni, M., van der Koore, N., Zijlstra, L.M., Kuipers, H.J., van Langevelde, F., et al. (2016) Strong Reactive Movement Response of the Medium-Sized European Hare to Elevated Predation Risk in Short Vegetation. Animal Behaviour, 115, 107-114. https://doi.org/10.1016/j.anbehav.2016.03.011

[23] Zhang, H., Li, W., Hu, Y. and Zhang, Y. (2015) Opposite Companion Effect on Flight Initiation Distance in Sympatric Species: Plateau Pika (Ochotona curzoniae) and White-Rumped Snowfinch (Onychostruthus taczanowskii). Canadian Journal of Zoology, 94, 109-114. https://doi.org/10.1139/cjz-2015-0126

[24] Brown, M. (2020) Detecting an Effect of Group Size on Individual Responses to Neighboring Groups in Gray-Cheeked Mangabeys (Lophocebus albigena). International Journal of Primatology, 41, 287-304. https://doi.org/10.1007/s10764-020-00144-9

[25] Deppe, A.M. (2020) Brown Mouse Lemurs (Microcebus rufus) May Lack Opportunities to Learn about Predator Calls. Folia Primatologica, 1-11. https://doi.org/10.1159/000505953

[26] Blumstein, D.T., Fernández-Juricic, E., Zollner, P.A. and Garity, S.C. (2005) Inter-Specific Variation in Avian Responses to Human Disturbance. Journal of Applied Ecology, 42, 943-953. https://doi.org/10.1111/j.1365-2664.2005.01071.x

[27] Frid, A. and Dill, L. (2002) Human-Caused Disturbance Stimuli as a Form of Predation Risk. Conservation Ecology, 6, 11. https://doi.org/10.5751/ES-00404-060111

[28] García-Arroyo, M. and MacGregor-Fors, I. (2020) Tolerant to Humans? Assessment of Alert and Flight Initiation Distances of Two Bird Species in Relation to Sex, Flock Size, and Environmental Characteristics. Ethology Ecology \& Evolution, 1-12. https://doi.org/10.1080/03949370.2020.1753115

[29] Cooper, W.E., Cooper Jr., W.E. and Blumstein, D.T. (2015) Escaping from Predators: An Integrative View of Escape Decisions. Cambridge University Press, Cambridge. https://doi.org/10.1017/CBO9781107447189

[30] Samia, D.S., Blumstein, D.T., Stankowich, T., Cooper Jr., W.E., et al. (2016) Fifty Years of Chasing Lizards: New Insights Advance Optimal Escape Theory. Biological Reviews, 91, 349-366. https://doi.org/10.1111/brv.12173

[31] Chassagneux, A., Calenge, C., Marchand, P., Richard, E., Guillaumat, E., Baubet, E., et al. (2020) Should I Stay or Should I Go? Determinants of Immediate and Delayed Movement Responses of Female Red Deer (Cervus elaphus) to Drive Hunts. PLoS $O N E, 15$, e228865. https://doi.org/10.1371/journal.pone.0228865

[32] Muposhi, V.K., Gandiwa, E., Makuza, S.M. and Bartels, P. (2016) Trophy Hunting and Perceived Risk in Closed Ecosystems: Flight Behaviour of Three Gregarious African Ungulates in a Semi-Arid Tropical Savanna. Austral Ecology, 41, 809-818. https://doi.org/10.1111/aec.12367

[33] Eason, P.K., Nason, L.D. and Alexander, J.E. (2019) Squirrels Do the Math: Flight Trajectories in Eastern Gray Squirrels (Sciurus carolinensis). Frontiers in Ecology and Evolution, 7, 66. https://doi.org/10.3389/fevo.2019.00066

[34] Cooper Jr., W.E. and Blumstein, D.T. (2013) Novel Effects of Monitoring Predators on Costs of Fleeing and Not Fleeing Explain Flushing Early in Economic Escape Theory. Behavioral Ecology, 25, 44-52. https://doi.org/10.1093/beheco/art083

[35] Blumstein, D.T., Samia, D.S., Stankowich, T. and Cooper Jr., W.E. (2015) 16. Best Practice for the Study of Escape Behavior. In: Cooper Jr., W.E., Ed., Escaping from 
Predators: An Integrative View of Escape Decisions, Cambridge University Press, Cambridge, 407-419. https://doi.org/10.1017/CBO9781107447189.017

[36] Zaman, M., Tolhurst, B., Zhu, M., Heng, B. and Jiang, G. (2019) Do Red Foxes (Vulpes vulpes) Increase the Detectability of Scent Marks by Selecting Highly Conspicuous Substrates? Journal of Ethology and Animal Science, 2, Article ID: 000113.

[37] Blumstein, D.T., Diaz, A. and Yin, L. (2018) Marmots Do Not Consistently Use Their Left Eye to Respond to an Approaching Threat but Those That Did Fled Sooner. Current Zoology, 64, 727-731. https://doi.org/10.1093/cz/zoy003

[38] Gorini, L., Linnell, J.D., May, R., Panzacchi, M., Boitani, L., Odden, M., et al. (2012) Habitat Heterogeneity and Mammalian Predator-Prey Interactions. Mammal Review, 42, 55-77. https://doi.org/10.1111/j.1365-2907.2011.00189.x

[39] Guo, K., Liu, H., Bao, H., Hu, J., Wang, S., Zhang, W., et al. (2017) Habitat Selection and Their Interspecific Interactions for Mammal Assemblage in the Greater Khingan Mountains, Northeastern China. Wildlife Biology, No. 4, 1-8. https://doi.org/10.2981/wlb.00261

[40] Blumstein, D.T. (2010) Flush Early and Avoid the Rush: A General Rule of Antipredator Behavior? Behavioral Ecology, 21, 440-442.

https://doi.org/10.1093/beheco/arq030

[41] Blumstein, D.T., Ebensperger, L., Hayes, L., Vásquez, R.A., Ahern, T.H., Burger, J.R., et al. (2010) Toward an Integrative Understanding of Social Behavior: New Models and New Opportunities. Frontiers in Behavioral Neuroscience, 4, 34. https://doi.org/10.3389/fnbeh.2010.00034

[42] Blumstein, D.T. and Munos, O. (2005) Individual, Age and Sex-Specific Information Is Contained in Yellow-Bellied Marmot Alarm Calls. Animal Behavior, 69 353-361. https://doi.org/10.1016/j.anbehav.2004.10.001

[43] Clutton-Brock, T., Gaynor, D., McIlrath, G., Maccoll, A., Kansky, R., Chadwick, P., et al. (1999) Predation, Group Size and Mortality in a Cooperative Mongoose, Suricata suricatta. Journal of Animal Ecology, 68, 672-683. https://doi.org/10.1046/j.1365-2656.1999.00317.x

[44] Fairbanks, B. and Dobson, F.S. (2007) Mechanisms of the Group-Size Effect on Vigilance in Columbian Ground Squirrels: Dilution versus Detection. Animal Behaviour, 73, 115-123. https://doi.org/10.1016/j.anbehav.2006.07.002

[45] Holtmeier, F.-K. (2015) Animals' Influence on the Landscape and Ecological Importance. Springer, Berlin. https://doi.org/10.1007/978-94-017-9294-3

[46] McLean, B.S. (2018) Urocitellus parryii (Rodentia: Sciuridae). Mammalian Species, 50, 84-99. https://doi.org/10.1093/mspecies/sey011

[47] Møller, A.P. (2008) Flight Distance and Population Trends in European Breeding Birds. Behavioral Ecology, 19, 1095-1102. https://doi.org/10.1093/beheco/arn103

[48] Tätte, K., Møller, A.P. and Mänd, R. (2018) Towards an Integrated View of Escape Decisions in Birds: Relation between Flight Initiation Distance and Distance Fled. Animal Behaviour, 136, 75-86. https://doi.org/10.1016/j.anbehav.2017.12.008

[49] Pulliam, H.R. (1973) On the Advantages of Flocking. Journal of Theoretical Biology, 38, 419-422. https://doi.org/10.1016/0022-5193(73)90184-7

[50] Hoogland, J.L. and Sherman, P.W. (1976) Advantages and Disadvantages of Bank Swallow (Riparia riparia) Coloniality. Ecological Monographs, 46, 33-58. https://doi.org/10.2307/1942393

[51] Hardie, S.M. and Buchanan-Smith, H.M. (1997) Vigilance in Single- and Mixed-Species Groups of Tamarins (Saguinus labiatus and Saguinus fuscicollis). International 
Journal of Primatology, 18, 217-234. https://doi.org/10.1023/A:1026372619340

[52] Carey, H.V. and Moore, P. (1986) Foraging and Predation Risk in Yellow-Bellied Marmots. American Midland Naturalist, 116, 267-275. https://doi.org/10.2307/2425734

[53] Blumstein, D.T., Runyan, A., Seymour, M., Nicodemus, A., Ozgul, A., Ransler, F., et al. (2004) Locomotor Ability and Wariness in Yellow-Bellied Marmots. Ethology, 110, 615-634. https://doi.org/10.1111/j.1439-0310.2004.01000.x

[54] Bischof, R., Ali, H., Kabir, M., Hameed, S. and Nawaz, M.A. (2014) Being the Underdog: An Elusive Small Carnivore Uses Space with Prey and Time without Enemies. Journal of Zoology, 293, 40-48. https://doi.org/10.1111/jzo.12100

[55] Roedenbeck, I.A. and Voser, P. (2008) Effects of Roads on Spatial Distribution, Abundance and Mortality of Brown Hare (Lepus europaeus) in Switzerland. European Journal of Wildlife Research, 54, 425-437. https://doi.org/10.1007/s10344-007-0166-3

[56] Santilli, F. and Galardi, L. (2016) Effect of Habitat Structure and Type of Farming on European Hare (Lepus europaeus) Abundance. Hystrix, 27, 1-3. 